\title{
Independent Factors Affecting Recovery Time After Sedation in Patients with Intellectual Disabilities
}

\author{
Shigeru Maeda ${ }^{1, *}$, Yumiko Tomayasu ${ }^{2}$, Hitoshi Higuchi ${ }^{1}$, Minako Ishii-Maruhama $^{1}$, \\ Ayaka Yamane ${ }^{1}$, Akiko Yabuki ${ }^{1}$, Yuka Honda ${ }^{2}$, Masahiko Egusa ${ }^{3}$ and Takuya Miyawaki ${ }^{2}$ \\ ${ }^{I}$ Department of Dental Anesthesiology, Okayama University Hospital. Okayama, Japan; ${ }^{2}$ Department of Dental Anes- \\ thesiology and Special Care Dentistry, Okayama University, Graduate School of Medicine, Dentistry and Pharmaceuti- \\ cal Sciences, Okayama, Japan; ${ }^{3}$ Special Needs Dentistry, Okayama University Hospital, Okayama, Japan
}

\begin{abstract}
Purpose: The purpose of this study was to identify independent factors associated with prolonged recovery time after intravenous sedation for dental treatment in patients with intellectual disabilities. Methods: This study was designed as a prospective cohort study. Participants were patients with intellectual disabilities, for whom sedation for dental treatment was planned in Okayama University Hospital. The outcome variable was recovery time. The predictor variables were patient background, antiepileptic and psychotropic drugs, and anesthesia-related variables. Factors affecting the outcome were examined with multiple regression analysis. Results: We enrolled 260 cases in this study. Oral midazolam was a strong independent determinant in prolonged recovery time. Teeth extraction, short treatment time and lower body mass index were significant independent predictors of prolonged recovery time. Conclusion: Oral midazolam is a clear independent determinant of prolonged recovery time after sedation, while psychotropic drugs and antiepileptic drugs were not independent determinants in this study.
\end{abstract}

Keywords: Anesthesia recovery period, intellectual disability, midazolam, propofol.

\section{INTRODUCTION}

Sedation is used for minor oral surgery and dental treatment in persons with severe intellectual disabilities [1, 2]. Patients with intellectual disabilities have a high rate of significant co-morbid conditions, such as epilepsy and mental disorders, which require daily medication that may influence the clinical effect of anesthetics used in sedation.

At present, propofol and midazolam are the primary agents used for sedation for dental treatment in patients with intellectual disabilities because of their short half-life and amnesic effects [3, 4]. However, because a significant number of these patients require a longer recovery time after sedation, it is thought that the interaction of factors such as concomitant medication and anesthetic choice may influence their recovery time. The pharmacokinetics of anesthetics are affected by drug-drug interactions [5-7], and the interactions are mainly mediated by cytochrome P450 (CYP) isoenzymes, so the anesthetics used in sedation are thought to be affected by antiepileptic and psychotropic drugs. Thus, the purpose of our study was to identify independent factors for prolonged recovery time after sedation using prospective multivariate analysis.

\section{MATERIALS AND METHODOLOGY}

\section{Study Design/Sample}

The investigators designed and implemented a prospective cohort study. The study population was composed of all

*Address correspondence to this author at the Department of Dental Anesthesiology, Okayama University Hospital, 2-5-1 Shikata-cho, Kita-ku, Okayama 700-8525, Japan; Tel/Fax: +81-86-235-6721;

E-mail:maedas@md.okayama-u.ac.jp patients presenting for evaluation and management of dental treatment under intravenous sedation in the clinic for Special Needs Dentistry in Okayama University Hospital from January 2011 to December 2011.

\section{Variables}

The outcome variable was recovery time, which was defined as the interval from termination of treatment until permission for discharge. We judged the patient's state of recovery using a post-anesthetic discharge scoring system [8] to estimate activity, vital signs, water intake, pain, and bleeding. Patients were permitted to be discharged when these factors had recovered to the same level as on admission. The subjects' recovery was evaluated by at least two dentists.

Predictor variables were age, gender, body mass index (BMI), daily use of representative antiepileptic or psychotropic drugs (carbamazepine, valproate, phenytoin, risperidone, haloperidol, and quetiapine), oral (PO) midazolam, amount of intravenous (IV) midazolam $(\mu \mathrm{g} / \mathrm{kg} \mathrm{BW})$, propofol rate $(\mu \mathrm{g} / \mathrm{kg} \mathrm{BW} / \mathrm{min})$, tooth extraction and treatment time (min).

\section{Anesthetic Procedure and Data Collection Methods}

As the patients had intellectual disabilities, written informed consent was obtained from parents or family members. Fasting times were $6 \mathrm{~h}$ for food and $2 \mathrm{~h}$ for clear water. Medicines in daily use were taken as usual. Intravenous sedation was started with insertion of an intravenous line, followed by injection of midazolam, and continuous injection of propofol was started in a target-controlled infusion (TCI) manner. The initial TCI value was set at $1.0-2.0 \mu \mathrm{g} / \mathrm{ml}$. When patients could not cooperate with the insertion because of their intellectual disabilities, $0.3-0.5 \mathrm{mg} / \mathrm{kg}$ of oral mida- 
zolam was given. After adequate sedation was obtained, an intravenous line was placed, followed by a continuous infusion of propofol as described above. In patients under 16 years of age, the propofol infusion was started at $5 \mathrm{mg} / \mathrm{kg} / \mathrm{h}(83.5 \mu \mathrm{g} / \mathrm{kg} / \mathrm{min})$ because TCI could not be used owing to the basic settings of the infusion pump.

Patients were continuously monitored with electrocardiograph, and for blood pressure and $\mathrm{SpO}_{2}$. During treatment, the sedation level was maintained at a score of 1-2 on the Modified Observer's Assessment of Alertness/Sedation Scale (MOAA/S) [9] by adjusting the target concentration of propofol. A score of 1 denotes "Does not respond to mild prodding or shaking" and a score of 2 denotes "Responds only after mild prodding or shaking". During treatment, local anesthetic containing $2 \%$ lidocaine and 1:80,000 adrenalin was used if it was considered necessary. After treatment was completed, the infusion of propofol was terminated. Patients were permitted to be discharged according to the standards outlined above.

The sedation was managed by dentists certified by the Japanese Dental Society of Anesthesiology. All data were collected by a person not in charge of anesthetic management. Patient information was de-identified and stored appropriately. This study was approved by the Ethics Committee, Okayama University, Graduate School of Medicine, Dentistry and Pharmaceutical Sciences (No.433), registered in the UMIN clinical trial registry (No. UMIN000006262), and conducted according to the Helsinki Declaration.

\section{Data Analysis}

Data were analyzed using JMP 9.0.0 (SAS Institute Inc., Cary, NC). Student's t-test was used between the primary outcome variable (recovery time) and the nominal variables, while a linear regression was applied to examine the bivariate regression between the outcome variable and continuous variables. To extract independent variables affecting the primary outcome, possible predictive variables were selected with stepwise regression, for which the cut-off was a $p$ value $<0.20$, followed by multiple regression analysis. The difference in the amount of IV midazolam used with oral midazolam and the amount used without oral midazolam was analyzed by Student's t-test.

\section{RESULTS}

Two hundred and sixty subjects (165 males and 95 females) were enrolled in this study. No patient was hospitalized after intravenous sedation and no major complications occurred. The average age of the subjects was 32.5 years. Recovery time was $62.8 \pm 25.8$ min (average \pm SD). Carbamazepine, valproate, phenytoin, risperidone, haloperidol and quetiapine were used in $86,80,38,21,86$ and 17 patients, respectively. As a premedication for sedation, oral midazolam was used in 38 cases, in which the amount of oral midazolam was $297 \pm 121 \mu \mathrm{g} / \mathrm{kg}$ (average $\pm \mathrm{SD}$ ). Tooth extraction was performed in 30 cases (Table 1). Among these variables, oral midazolam was significantly correlated with recovery time, but there was no significant difference between recovery time and other variables, such as antiepileptic or psychotropic drugs.
Table 1. Differences in time to recovery from the sedation by nominal variables.

\begin{tabular}{|c|c|c|c|}
\hline \multirow{2}{*}{ Variables (No. of patients) } & \multicolumn{3}{|c|}{ Recovery time (min) } \\
\hline & Average & SD & p value \\
\hline Gender & & & 0.928 \\
\hline male (165) & 63.1 & 27.6 & \\
\hline female (95) & 62.8 & 24.8 & \\
\hline Carbamazepine & & & 0.672 \\
\hline yes $(86)$ & 61.9 & 25.8 & \\
\hline no (174) & 63.3 & 25.9 & \\
\hline Valproate & & & 0.550 \\
\hline yes $(80)$ & 64.3 & 27.4 & \\
\hline no (180) & 62.2 & 25.1 & \\
\hline Phenytoin & & & 0.235 \\
\hline yes (38) & 58.3 & 19.8 & \\
\hline no (222) & 63.6 & 26.7 & \\
\hline Risperidone & & & 0.527 \\
\hline yes (48) & 60.7 & 21.8 & \\
\hline no (172) & 63.3 & 26.7 & \\
\hline Haloperidol & & & 0.199 \\
\hline yes (21) & 69.8 & 32.8 & \\
\hline no (239) & 62.3 & 25.1 & \\
\hline Quetiapine & & & 0.166 \\
\hline yes (17) & 54.5 & 8.8 & \\
\hline no (243) & 63.4 & 26.5 & \\
\hline Oral Midazolam & & & $<0.001$ \\
\hline yes (38) & 88.8 & 37.5 & \\
\hline no (222) & 58.4 & 20.2 & \\
\hline Extraction & & & 0.099 \\
\hline yes (30) & 70.2 & 30.8 & \\
\hline no $(230)$ & 61.9 & 25.0 & \\
\hline
\end{tabular}

The average amount of IV midazolam and the propofol rate were $29.3 \mu \mathrm{g} / \mathrm{kg}$ and $43.1 \mu \mathrm{g} / \mathrm{kg} / \mathrm{min}$, respectively. Treatment time was $43.1 \pm 12.5$ min (average \pm SD). Among the five continuous variables analyzed in this study, only the amount of IV midazolam was significantly and negatively correlated with recovery time (Table 2).

Using stepwise regression, haloperidol, oral midazolam, extraction, BMI, amount of IV midazolam, propofol rate and treatment time were selected for a standard least squares calculation, in which oral midazolam was shown to be strongly associated with prolonged recovery time. Lower BMI, tooth extraction, and shorter treatment time were also 
Table 2. Continuous variables and their relationship to time to recovery from the sedation.

\begin{tabular}{|c|c|c|c|c|c|c|}
\hline \multirow{3}{*}{ Variables } & \multirow{3}{*}{ Average } & \multirow{3}{*}{ SD } & \multicolumn{4}{|c|}{ Correlation with Time to Recovery } \\
\hline & & & \multirow[t]{2}{*}{$\begin{array}{l}5 \% \\
\text { Upper } 95 \%\end{array}$} & \multicolumn{2}{|l|}{$\begin{array}{l}\text { Age (yrs) } \\
32.4 \\
11.6\end{array}$} & \multirow[t]{2}{*}{-0.018} \\
\hline & & & & Lower 95\% & Upper $95 \%$ & \\
\hline Age (yrs) & 32.4 & 11.6 & -0.018 & -0.139 & 0.104 & 0.775 \\
\hline Amount of IV midazolam $(\mu \mathrm{g} / \mathrm{kg})$ & 29.3 & 17.8 & -0.289 & -0.397 & -0.173 & $<0.001$ \\
\hline Propofol rate $(\mu \mathrm{g} / \mathrm{kg} / \mathrm{min})$ & 98.2 & 31.8 & -0.005 & -0.157 & 0.231 & 0.930 \\
\hline Treatment time (min) & 43.1 & 12.5 & -0.111 & -0.170 & 0.219 & 0.072 \\
\hline
\end{tabular}

Table 3. Stepwise logistic regression model for time to recovery from intravenous sedation.

\begin{tabular}{|l|l|l|l|l|}
\hline Variable & Estimate & SE & t value & p value $($ Prob $>|\mathbf{t}|)$ \\
\hline \hline Intercept & 124.337 & 12.454 & 9.98 & $<0.001 *$ \\
\hline Haloperidol (yes or no) & 3.460 & 2.644 & 1.31 & 0.192 \\
\hline Oral Midazolam (yes or no) & 14.235 & 2.644 & 5.38 & 2.74 \\
\hline Extraction (yes or no) & 6.120 & 2.237 & -2.74 & $0.007 *$ \\
\hline BMI $\left(\mathbf{k g} / \mathbf{m}^{2}\right)$ & -0.920 & 0.335 & -1.41 & $0.007 *$ \\
\hline Amount of IV midazolam $(\mathbf{m g} / \mathbf{k g})$ & -0.156 & 0.111 & -1.48 & 0.161 \\
\hline Propofol rate $(\boldsymbol{\mu g} / \mathbf{k g} / \mathbf{m i n})$ & -0.068 & 0.046 & -2.59 & 0.141 \\
\hline Treatment time (min) & -0.299 & 0.115 & & $0.010^{*}$ \\
\hline $\mathrm{R}^{2}=0.238$, Significant parameter. & & & \\
\hline
\end{tabular}

shown to be independent determinants of prolonged recovery time (Table 3). However, antiepileptic and/or psychotropic drugs were not independent predictor variables of recovery time.

The amount of IV midazolam used was significantly less in subjects who did not take oral midazolam (Table 4).

Table 4. Differences in amount of IV midazolam by Oral midazolam (yes or no).

\begin{tabular}{|l|l|l|l|}
\hline \multirow{2}{*}{ Variables (No. of patients) } & \multicolumn{3}{|l|}{ Amount of IV Midazolam $(\boldsymbol{\mu g} / \mathbf{k g})$} \\
\cline { 2 - 4 } & Mean & SD & p value \\
\hline \hline Oral Midazolam (yes or no) & & & $<0.0001$ \\
\hline yes (38) & 1.9 & 6.8 & \\
\hline no (222) & 34.0 & 14.6 & \\
\hline
\end{tabular}

\section{DISCUSSION}

The results of this study show that oral midazolam is a clear independent predictor of prolonged recovery time after sedation. The average amount of oral midazolam in partici- pants who used oral midazolam as a premedication was $297 \pm 121 \mu \mathrm{g} / \mathrm{kg}$, which is almost 10 times higher than the average amount of IV midazolam $(29.3 \pm 17.8 \mu \mathrm{g} / \mathrm{kg})$. In a previous report, $2 \mathrm{mg}$ of IV midazolam brought about the same level of plasma concentration as $7.5 \mathrm{mg}$ of oral midazolam [10], suggesting that 10 times the amount of oral midazolam directly contributes to prolonged recovery time after sedation. Antiepileptic and psychotropic drugs, the amount of IV midazolam, and the propofol rate were not independent determinants. Although the amount of IV midazolam was negatively correlated with recovery time in bivariate regression, it is considered to be a confounding factor because there was a significant difference in the amount of IV midazolam used, depending on whether oral midazolam was used.

Participants used a variety of antiepileptic and antipsychotic drugs. Although common side effects of these drugs are sleepiness and/or drowsiness, the drugs were not independent factors for prolonged recovery time after sedation. In this study, oral or IV midazolam were used for all participants. This may have masked the effect of the antiepileptic and antipsychotic drugs after sedation, and these drugs were not shown to be independent factors for prolonged recovery time. 
Shorter treatment time was shown to be another independent predictor of prolonged recovery time. This may be the result of residual midazolam effects. Oral midazolam was used as a premedication, and IV midazolam was administered at the beginning of the sedation. As the half-life of midazolam is longer than that of propofol [11], shorter treatment time would mean more prominent midazolam effects at the beginning of the recovery time, requiring a longer duration for metabolic clearance.

BMI was negatively correlated with recovery time in this study. Although the person responsible for the sedation kept the anesthesia level at class 1-2 in the MOAA/S scale, the upper airway of an obese person is more easily obstructed than that of a non-obese person at the same level of sedation, as described previously by Wani et al. [12]. Accordingly, to maintain the airway safely, the sedation level in an obese person might be lighter than that in a non-obese person. This might explain the negative correlation of BMI with recovery time. Tooth extraction was another independent predictor of prolonged recovery time. This is considered to be a reflection of a delay in discharge permission to comply with the post-anesthetic discharge scoring system, in which achieving hemostasis was a requirement. Because bleeding is specific in tooth extraction, this was considered to cause tooth extraction to be an independent factor for prolonged recovery time.

In this study, oral midazolam was a strong predictor for prolonged recovery time after sedation, but interactions between anesthetics and antiepileptic and/or psychotropic drugs were not observed. In a clinical situation, the interaction of these medications may be ignored when assessing recovery from sedation. To detect further interactions, it would be necessary to measure plasma concentrations of the anesthetics or instigate a more sophisticated research design.

\section{CONCLUSION}

Oral midazolam is a clear independent determinant of prolonged recovery time after sedation for dental treatment in patients with intellectual disabilities, while psychotropic drugs and antiepileptic drugs were not independent determinants in this study.

\section{CONFLICT OF INTEREST}

The authors confirm that this article content has no conflict of interest.

\section{ACKNOWLEDGEMENTS}

This research was funded by the Japanese Ministry of Health, Labour and Welfare (H22-shintai/chiteki-ippan-008) and the Grant-in-Aid for Scientific Research (C) (25463135).

\section{REFERENCES}

[1] Sakaguchi M, Higuchi H, Maeda S, Miyawaki T. Dental sedation for patients with intellectual disability: a prospective study of manual control versus Bispectral Index-guided target-controlled infusion of propofol. J Clin Anesth 2011; 23: 636-42.

[2] McQuaid KR, Laine L. A systematic review and meta-analysis of randomized, controlled trials of moderate sedation for routine endoscopic procedures. Gastrointest Endosc 2008; 67: 910-23.

[3] Padmanabhan U, Leslie K, Eer AS, Maruff P, Silbert BS. Early cognitive impairment after sedation for colonoscopy: the effect of adding midazolam and/or fentanyl to propofol. Anesth Analg 2009; 109: 1448-55.

[4] Wahidi MM, Jain P, Jantz M, et al. American College of Chest Physicians consensus statement on the use of topical anesthesia, analgesia, and sedation during flexible bronchoscopy in adult patients. Chest 2011; 140: 1342-50.

[5] Ishii M, Higuchi H, Maeda S, Tomoyasu Y, Egusa M, Miyawaki T. The influence of oral VPA on the required dose of propofol for sedation during dental treatment in patients with mental retardation: a prospective observer-blinded cohort study. Epilepsia 2012; 53: e136.

[6] Walzer M, Bekersky I, Blum RA, Tolbert D. Pharmacokinetic drug interactions between clobazam and drugs metabolized by cytochrome P450 isoenzymes. Pharmacotherapy 2012; 32: 340-53.

[7] Ohmori J, Maeda S, Higuchi H, et al. Propofol increases the rate of albumin-unbound free midazolam in serum albumin solution. J Anesth 2011; 25: 618-20.

[8] White PF, Eng MR. Ambulatory (outpatient) anesthesia. In: Miller RE, editor. Anesthesia $7^{\text {th }}$ ed. Philadelphia: Churchill Livingstone Elsevier; 2010. p. 2419-59.

[9] Shah N, Vargo JJ. Basic requirements of gastroenterologists to treat upper gastrointestinal bleeding: competency and sedation issues. Gastrointest Endosc Clin N Am 2011; 21: 731-7.

[10] Link B, Haschke M, Grignaschi N, et al. Pharmacokinetics of intravenous and oral midazolam in plasma and saliva in humans: usefulness of saliva as matrix for CYP3A phenotyping. Br J Clin Pharmacol 2008; 66: 473-84.

[11] Fassoulaki A, Theodoraki K, Melemeni A. Pharmacology of sedation agents and reversal agents. Digestion 2010; 82: 80-3.

[12] Wani S, Azar R, Hovis CE, et al. Obesity as a risk factor for sedation-related complications during propofol-mediated sedation for advanced endoscopic procedures. Gastrointest Endosc 2011; 74: $1238-47$.

\footnotetext{
Received: January 02, 2015

Revised: March 18, 2015

Accepted: March 20, 2015

(C) Maeda et al.; Licensee Bentham Open.

This is an open access article licensed under the terms of the Creative Commons Attribution Non-Commercial License (http://creativecommons.org/licenses/by-nc/3.0/) which permits unrestricted, non-commercial use, distribution and reproduction in any medium, provided the work is properly cited.
} 